Research Article

\title{
Drug utilization 90\%: an innovative method in assessing quality of drug prescription with specific reference to non-steroidal anti-inflammatory drugs prescription
}

\author{
Dhananjay Kulkarni ${ }^{1 *}$, Kokila B. N. ${ }^{2}$, Santosh Kumar Sahu ${ }^{3}$, Ravindra Kumar G. ${ }^{1}$
}

\begin{abstract}
${ }^{1}$ Department of Pharmacology, Konaseema Institute of Medical Sciences and Research Foundation (KIMS \& RF), Amalapuram, Andhra Pradesh, India,

${ }^{2}$ Department of Pharmacology, KVG Medical College, Sullia (DK), Karnataka, India, ${ }^{3}$ Department of Orthopaedics Konaseema Institute of Medical Sciences and Research Foundation (KIMS and RF), Amalapuram, Andhra Pradesh, India
\end{abstract}

Received: 12 August 2016 Accepted: 16 August 2016

*Correspondence to: Dr. Kulkarni Dhananjay, Email: ksdhanu@rediffmail.com

Copyright: () the author(s), publisher and licensee Medip Academy. This is an openaccess article distributed under the terms of the Creative Commons Attribution NonCommercial License, which permits unrestricted noncommercial use, distribution, and reproduction in any medium, provided the original work is properly cited.

\begin{abstract}
Background: DU90\% is useful tool for assessing drug prescribing pattern. In this, drugs constituting $90 \%$ of the prescription volume are identified. Size of the DU90\% segment helps us to assess rational prescribing. Large number of drugs in the DU90\% segment indicates less rational prescribing, whereas small number suggests more rational prescribing.

Methods: Study was carried out in orthopaedic out-patient department (OPD) for a period of three months. Only OPD based NSAID containing prescriptions were included. Data was analyzed based on demographic parameters, prescription indices, fixed dose combinations (FDC) and co-prescription of gastro-protective agents (GPA). DU90\% was calculated based on defined daily dose (DDD) with their respective value in Anatomical Therapeutic Chemical (ATC) classification code. Defined daily dose is calculated as DDD/1000/day.

Results: Diclofenac (38\%) was the commonest NSAID prescribed. Diclofenac +chymotrypsin (25\%) was the commonest FDC prescribed. Piroxicam (19\%) was the commonest NSAID prescribed in monotherapy form. Co-prescription of GPA was high (96\%). 5 of the 7 prescribed NSAIDs constitute to DU90\% segment.

Conclusions: Preferential cyclooxygenase-2 (COX-2) inhibitor NSAIDs were more preferred. Number of prescribed NSAIDs constituting to DU90\% is more, thus prescription pattern needs further rationalization. Further large scale study is required to bring out more details about NSAID prescription pattern and its rational use.
\end{abstract}

Keywords: DU90\%, FDC, DDD, NSAID, Prescription pattern, GPA

\section{INTRODUCTION}

DU90\% is an innovative approach to assess drug prescribing. Using this approach, the drugs that represent $90 \%$ of the drug prescription/sales volume are identified. ${ }^{1}$ The rationale behind the development of DU90\% rests on an assumption that a low number of products prescribed is associated with more rational prescribing practices. Furthermore, the approach can be used to assess what proportion of the drugs that represent $90 \%$ of the volume is made up by drugs listed in essential drug list. ${ }^{2}$ 
DU90\% does not directly reflect the quality of prescribing but it seems to be a useful tool in the quality assessment process through indicating areas that need to be analysed in more depth. The approach can be used for exploring drug prescribing data in a rapid, effective and inexpensive way. ${ }^{3}$ DU90\% identifies the number of drugs making up to $90 \%$ of the total volume, measured in Defined Daily Dose (DDD) or number of prescriptions (NP), during a certain period of time. According to DU90\% concept a physician using few, well known and proved drug alternatives in the daily practice, would provide a more rational prescribing and hence a higher quality of care. It is a purely descriptive prescription indicator. ${ }^{4}$ Size of the DU90\% segment helps us to assess rational prescribing. A very large number of drugs in the DU90\% segment indicate less rational prescribing. On the other hand, a small number of drugs in DU90\% could suggest a more rational prescribing. The assumption that less is better is used as prescribing indicator in DU90\%. ${ }^{2}$

The defined daily dose (DDD) is the assumed average maintenance dose per day for a drug used for its main indication in adults. It will only be assigned for drugs that already have an anatomical therapeutic chemical (ATC) classification code. DDD is a unit of measurement and does not necessarily reflect the recommended or prescribed daily dose. ${ }^{5}$ Drug consumption data presented in DDDs only give a rough estimate of consumption and not exact picture of actual use. DDDs are not established for topical preparations, sera, vaccines, anti-neoplastic agents, allergen extracts, general and local anaesthetics and contrast media. ${ }^{4}$ DDD is most commonly calculated as DDD/1000/day.

The treatment of pain and inflammation is an important area of therapeutics. Over the past two decades, nonsteroidal anti-inflammatory drugs (NSAIDs) have played a central role in these indications. NSAIDs constitute the largest single group of drugs used worldwide, constituting more than $20 \%$ of all drug prescriptions. ${ }^{6}$ In India over 400 formulations of NSAIDs are marketed, resulting in wide spread exposure of patients to this class of drugs and its adverse effects. ${ }^{7}$ Hence studies that evaluate the pattern, extent and frequency of NSAID prescriptions are valuable, thus in this regard this present study attempts to assess NSAID prescription pattern using DU90\% methodology.

\section{METHODS}

A prospective, non-interventional, cross sectional (observational) study was carried out in the out-patient department of orthopaedics, Konaseema Institute of Medical Sciences (KIMS), Amalapuram, Andhra Pradesh. Necessary Institutional ethics committee clearance for the conduct of the study was taken. The study was conducted over a period of three months (March to May 2016). During the study period NSAIDs containing prescriptions were included in the study. Prescriptions of in-patients, surgical intervention patients, serious life threatening injury patients or patients who refuse to give consent for the screening of their prescriptions were not included.

Since it was a non-invasive and descriptive study, patient's willingness to screen their prescription will be considered as their consent. Due co-operation from the staff of orthopaedic department was sought. Personal details of the patients were kept confidential. All the relevant prescription data was noted down in a specialized proforma for Microsoft excel entry.

Descriptive statistical analysis of the data using tabular forms, percentage and bar diagrams was done. Data on demographic parameters, prescription indices, fixed dose combinations and gastro-protective drugs was high lightened. DU90\% was calculated based on number of prescriptions as well as by defined daily dose (DDD) with their respective value in anatomical therapeutic chemical (ATC) classification code. Here Defined daily dose is calculated as DDD/1000/day and the formula used was:

$\frac{\frac{\text { DDD }}{1000}}{\text { day }}=\frac{\text { Total no of dosage units prescribed X strength of each dosage }}{\text { DDD X duration of study X total sample size }}$

\section{RESULTS}

Overall 200 NSAIDs containing prescriptions were included in this study. Female cases $(56 \%)$ were more than male counterparts. Maximum cases (48\%) belong to 26 years to 59 years of age group. Table 1 highlights demographic profile and prescription indices of the present study. Number of NSAIDs prescribed in 200 prescriptions was 248; hence average NSAID prescribed per prescription was 1.24. Antibiotics were prescribed in 40 prescriptions. Calcium supplementations were prescribed to 120 cases; mainly to above 40 year female patients.

In this study NSAIDs were prescribed both as monotherapy and as FDCs. Monotherapy was prescribed in 88 cases and FDCs to 160 cases. Table $2 \mathrm{~A}$ shows details of NSAID containing FDCs. Diclofenac+chymotrypsin $(25 \%)$ was the commonest FDC prescribed, followed by etodolac+paracetamol (20\%) combination. Thiocolchicoside was the commonest non-NSAID component found in FDC. Paracetamol was only prescribed (72) in FDC form, either with other NSAIDs (48) or with tramadol (24). In this study coprescription of Gastro-protective agents (GPA) was high. Table 2B shows details of GPA co-prescription. Almost all NSAID prescriptions (96\%) were associated with GPA co-prescription. Ranitidine was the commonest GPA $(83.33 \%)$ prescribed.

Figure 1 shows details of NSAIDs prescribed in monotherapy and in FDC form. Piroxicam, indomethacin and lornoxicam were only prescribed in monotherapy 
form, whereas etodolac, paracetamol and aceclofenac were only prescribed in FDC form.

Table 1: Demographic profile and prescription indices.

\begin{tabular}{|ll|}
\hline Demographic profile & $200(\mathrm{n})$ \\
\hline Total sample size & 88 \\
\hline Male & 112 \\
\hline Female & \\
\hline Age & 56 \\
\hline 25 years and below & 96 \\
\hline $26-59$ years & 48 \\
\hline 60years and above & 728 \\
\hline Prescription indices & 3.64 \\
\hline Total number of drugs prescribed & 120 \\
\hline Average Number of drugs per prescription & 1.24 \\
\hline $\begin{array}{l}\text { Number of prescription containing calcium } \\
\text { supplementation. }\end{array}$ & 160 \\
\hline $\begin{array}{l}\text { Average number of NSAIDs per } \\
\text { prescription }\end{array}$ & 88 \\
\hline $\begin{array}{l}\text { Number of FDCs containing NSAIDs } \\
\text { prescribed }\end{array}$ & 08 \\
\hline $\begin{array}{l}\text { Number of NSAIDs prescribed in } \\
\text { monotherapy form }\end{array}$ & 40 \\
\hline Number of analgesic gel prescribed & \\
\hline Number of antibiotics prescribed & \\
\hline
\end{tabular}

Table 2: Details of NSAID containing FDCs and coprescription of GPA.

\begin{tabular}{|lll|}
\hline A. Fixed Dose combinations of NSAIDs \\
\hline FDC of NSAIDs & $\begin{array}{l}\text { Number of } \\
\text { prescriptions }\end{array}$ & $\begin{array}{l}\text { Percentage } \\
(\mathbf{n}=\mathbf{1 6 0})\end{array}$ \\
\hline $\begin{array}{l}\text { Diclofenac }+ \\
\text { chymotrypsin }\end{array}$ & 40 & 25 \\
\hline $\begin{array}{l}\text { Etodolac }+ \\
\text { Paracetamol }\end{array}$ & 32 & 20 \\
\hline $\begin{array}{l}\text { Etodolac }+ \\
\text { Thiocolchicoside }\end{array}$ & 24 & 15 \\
\hline $\begin{array}{l}\text { Tramadol }+ \\
\text { Paracetamol }\end{array}$ & 24 & 15 \\
\hline $\begin{array}{l}\text { Aceclofenac }+ \\
\text { thiocolchicoside }\end{array}$ & 24 & 15 \\
\hline $\begin{array}{l}\text { Aceclofenac }+ \\
\text { Paracetamol }\end{array}$ & 16 & 10 \\
\hline $\begin{array}{l}\text { B. Co-prescription of gastro-protective agents } \\
\text { (GPA) }\end{array}$ & $\begin{array}{l}\text { Number of } \\
\text { Prescriptions }\end{array}$ & $\begin{array}{l}\text { Percentage } \\
\text { (n = 192) }\end{array}$ \\
\hline $\begin{array}{l}\text { GPA drug } \\
83.33\end{array}$ \\
\hline Ranitidine & 160 & 16.67 \\
\hline Pantoprazole & 32 & \\
\hline
\end{tabular}

Diclofenac was the only NSAID which was prescribed in both forms. Piroxicam was the commonest NSAID prescribed in monotherapy form. Etodolac was the commonest NSAID prescribed in FDC form. With the combination of both forms, overall Diclofenac (76) was the commonest NSAID prescribed followed by etodolac (56), aceclofenac (40), piroxicam (38), paracetamol (24), Indomethacin (8) and lornoxicam (6) respectively. Number of paracetamol FDCs prescribed were 72, of these 24 was with tramadol combination. Only these 24 FDCs were shown in Figure 1, as the rest 48 FDCs were with other NSAIDs like etodolac and aceclofenac and are already included in their respective sections.

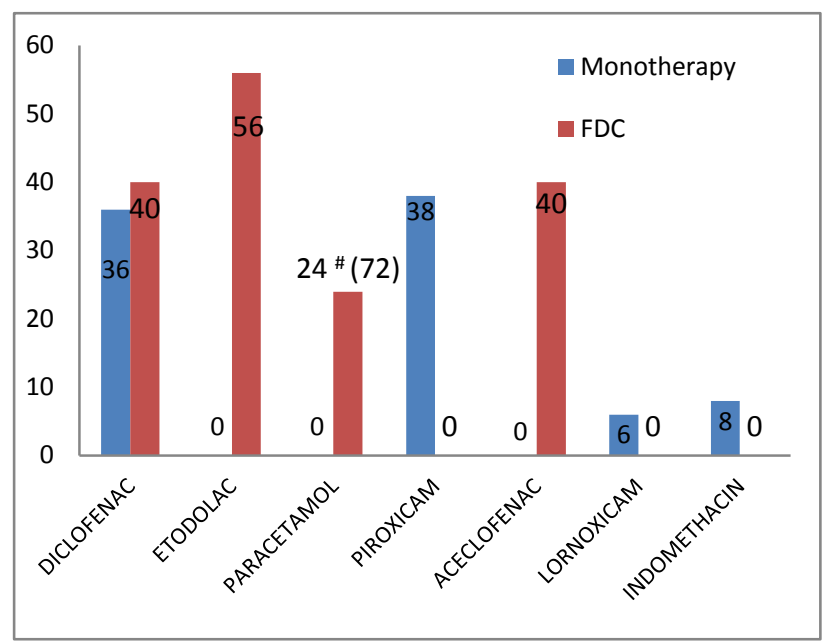

\#Overall paracetamol FDCs were 72, of this 24 is with tramadol and is shown in figure, rest 48 is with other NSAIDs like etodolac and aceclofenac and thus already included in their respective sections.

Figure 1: Details of NSAIDs prescribed in FDC and in monotherapy form.

Table 3 shows various indications for NSAID prescription in this study. Low backache $(28 \%)$ was the commonest indication, followed by joint sprain $(21.5 \%)$, trauma $(18 \%)$ and others $(32.5 \%)$ respectively.

Table 3: Indications for NSAID prescription.

\begin{tabular}{|lll|}
\hline $\begin{array}{l}\text { Clinical } \\
\text { conditions }\end{array}$ & $\begin{array}{l}\text { No. of } \\
\text { prescriptions }\end{array}$ & $\begin{array}{l}\text { Percentage } \\
(\mathbf{n = 2 0 0 )}\end{array}$ \\
\hline Low backache & 56 & 28 \\
\hline Joint sprains & 43 & 21.5 \\
\hline Trauma & 36 & 18 \\
\hline $\begin{array}{l}\text { Tendinits and } \\
\text { bursitis }\end{array}$ & 30 & 15 \\
\hline Arthritides & 29 & 14.5 \\
\hline Others & 06 & 03 \\
\hline
\end{tabular}

Table 4 shows details of drug constituting DU90\% (based on number of prescription and DDD). For each drug defined daily dose (DDD) and ATC code was provided. DDD/1000/days was calculated as per its formula for each drug. Out of seven different NSAID prescribed, five of them constitute to DU90\% and these are diclofenac, etodolac, aceclofenac, paracetamol and piroxicam respectively. Only indomethacin and lornoxicam were out of purview of DU90\%. 
Table 4: Details of NSAIDs constituting to DU90\%.

\begin{tabular}{|c|c|c|c|c|}
\hline Drugs & ATC CODE & DDD & No. of prescription ( $\left.n=248^{*}\right)$ & DDD/1000/days \\
\hline Diclofenac & M01AB05 & $100 \mathrm{mg}$ & 76 & 29.56 \\
\hline Etodolac & M01AB08 & $400 \mathrm{mg}$ & 56 & 43.55 \\
\hline Aceclofenac & M01AB16 & $200 \mathrm{mg}$ & 40 & 15.56 \\
\hline $\begin{array}{l}\text { Paracetamol FDC } \\
\text { With other NSAIDs }\left(48^{* *}\right) \\
\text { and } \\
\text { With Tramadol (24) }\end{array}$ & N02BE71 & $325 \mathrm{mg}$ & 24 & 18.67 \\
\hline Piroxicam & M01AC01 & $20 \mathrm{mg}$ & 38 & 14.77 \\
\hline Indomethacin & M0IAB01 & $100 \mathrm{mg}$ & 08 & 3.11 \\
\hline Lornoxicam & M01AC05 & $12 \mathrm{mg}$ & 06 & 3.11 \\
\hline
\end{tabular}

*Here $\mathrm{n}$ is 248 as some prescriptions has more than one NSAID, although total number of prescriptions for the study were 200 . Hence average NSAIDs prescribed per prescription was 1.24 .

$* * 48$ is not part of the calculation, as NSAID in these FDCs of paracetamol is taken as principal component and is already included in their respective column.

\section{DISCUSSION}

The study was conducted in out-patient orthopaedic department for a period of three months. Overall 200 NSAID containing prescriptions were included and analyzed in this study. Overall diclofenac was the commonest NSAID prescribed in this study, same trend was observed in Dhaka prescription study. ${ }^{8}$ Similarly diclofenac was also the commonest NSAID prescribed in a study conducted by VS Manohar et al. ${ }^{9}$ In this present study none of the selective cyclooxygenase-2 (COX-2) inhibitors were prescribed, instead preferential COX-2 inhibitors (diclofenac, etodolac and aceclofenac) and traditional NSAIDs (like piroxicam) were more preferred. $^{10}$

High frequency of preferential COX-2 inhibitor and nonselective NSAID prescription points towards the changing trends observed in the prescriber's preference for NSAID prescription after the withdrawal of rofecoxib. ${ }^{11}$ This changing trend might be due to increased awareness and recent reports of cardiovascular (CVS) complications associated with various selective COX-2 inhibitors. ${ }^{9}$ Similarly a study conducted in New York, shows that COX-2 inhibitors constituted 37\% of NSAID prescription before the withdrawal of rofecoxib. After withdrawal, their frequency decreased to $16 \%$ within one year and progressively decreased further in follow up studies. ${ }^{12}$

Low backache was the commonest indication for NSAID prescription. Similar indication is seen in other studies, like in Dhaka study, where low backache and trauma were the commonest indications for NSAIDs; another study in Dhaka also shows similar findings. ${ }^{8,13}$ Present study shows high prevalence of co-prescription of GPAs (96\%). High frequency of GPA prescription can be attributed to prescriber's preference for non-selective NSAIDs, which are more prone to cause gastritis and peptic ulceration. Similar high trend was also observed in two different Spanish studies where frequency of GPAs co-prescription was $64 \%$ and $85 \%$ respectively. ${ }^{14,15}$ This high coprescription of GPA can also be attributed to defensive trend observed by prescribers in order to decrease NSAID induced complication, especially after the withdrawal of rofecoxib. ${ }^{16}$ In our study ranitidine was the commonest GPA prescribed and was more preferred than pantoprazole, unlike the study done by VS Manohar et al where proton pump inhibitors were more preferred. ${ }^{9}$

In this study NSAID containing FDCs are prescribed in large numbers $(n=160)$. Diclofenac+Chymotrypsin combination is the commonest FDC prescribed followed by Etodolac+Paracetamol, aceclofenac+paracetamol, tramadol + paracetamol and others. This high prevalence of FDC prescription is similar to a study conducted in Uttaranchal, where FDC prescription frequency was more than $49 \% .{ }^{17}$ A similar combination of NSAID FDCs were also prescribed in Ahmedabad study. ${ }^{18}$ However many combination of NSAID as FDCs is not recommended as these combinations have no drug synergism and moreover the combination can increase the chances of adverse events and overall cost of prescribing. ${ }^{19}$ Nevertheless some useful analgesic combinations do exist, such as combination of tramadol with paracetamol. They synergise with each other as site of actions are different for both the drugs. ${ }^{20}$

The anatomical therapeutic chemical (ATC) classification divides drugs into different groups according to the organ or system on which they act and their chemical, pharmacological and therapeutic properties. ${ }^{21}$ The DDD is the assumed average maintenance dose for a drug used for its main indication in adults. The DDD provides a fixed unit of measurement that is independent of price and formulation, and makes it easier to compare drug 
utilisation across studies. The major benefit of studying drug utilization using DDD is that the dosage and the duration of use are both factored in to the calculation. The dosage, frequency and duration of use are variable in different patients, and these differences can be overcome by using the DDD as a measure of drug consumption. ${ }^{22}$ DU90\% which can also be expressed in terms of DDD, basically assess what number of drugs constitutes to $90 \%$ of prescription, less the number of drugs constituting DU90\%, more rational is the prescribing. ${ }^{2}$

Five of the seven NSAIDs prescribed in this study constitute to DU90\%. As more drugs constitute to DU90\%; prescription pattern needs further rationalization. In this study only preferential COX-2 inhibitors and traditional NSAIDs are part of DU90\%. This finding is similar to study done by J Ćalasan et al where only preferential COX-2 inhibitors were part of DU90\%. ${ }^{23}$ Contrary to our result COX-2 inhibitors were the major constituents of DU90\% in Korean study. ${ }^{24}$ Similarly in PGI Chandigarh, before the withdrawal of rofecoxib, COX-2 inhibitors were the major component of DU90\%. ${ }^{25}$

After the withdrawal of rofecoxib (2004) and subsequent news of increased CVS adverse effect seen with selective COX-2 inhibitors, prescribers increasingly replaced COX2 inhibitors with non-selective NSAIDs and preferential COX2 inhibitors, considering it as a class effect and not as individual drug effect. ${ }^{26}$ This observation can very well be noted in our study as DU90\% segment is mainly constituted by preferential COX-2 inhibitors and nonselective NSAIDs.

\section{CONCLUSION}

DU90\% is one of the innovative tool for assessing drug prescribing pattern. It also helps in understanding drug utilization over a period of time. In this study, of the seven NSAIDs, five were part of DU90\%. As more drug constitute to DU90\%; prescription pattern needs further rationalization. Preferential COX-2 inhibitors were more preferred than selective COX-2 inhibitors. Large scale study of DU90\% with involvement of more departments will help further to highlight prescription pattern of NSAIDs and its rational use.

Funding: No funding sources

Conflict of interest: None declared

Ethical approval: The study was approved by the Institutional Ethics Committee

\section{REFERENCES}

1. Teichert M, Van der Aalst A, De Wit H, Stroo M, De Smet P. How useful are prescribing indicators based on the $90 \%$ method to distinguish the quality of prescribing between pharmacotherapy audit meeting with different level of functioning. Eur $\mathbf{J}$ Clin Pharmacol. 2007;63:1171-2.
2. Bergman U, Popa C, Tomson Y, Wettermark B, Einarson TR, Aberg H, Sjoqvist F. Drug utilization $90 \%$-a simple method for assessing the quality of drug prescribing. Eur J Clin Pharmacol. 1998;54(2):113-8.

3. Bergman ULF. Pharmacoepidemiology-from description to quality assessment: A Swedish perspective. Norwegian J Epidemiol. 2001;11(1):316.

4. Popa C. DU90\% for the assessment of drug prescribing in primary care. Master of Pub Health (MPH). 2005;18:17-8.

5. Grimmsmann T, Wolfgang H. Discrepancies between prescribed and defined daily doses: a matter of patients or drug classes? Eur J Clin Pharmacol. 2011;11:1014-7.

6. Pincus T, Swearingen C, Cunmine P, Callahaw LP. Preference for non-steroidal anti-inflammatory drugs versus acetaminophen and concomitant use of both types of drugs in patients with osteoarthritis. J Rheumatol. 2000;27:1020-7.

7. Paul AD, Chauhan CK. Study of usage pattern of nonsteroidal anti-inflammatory drugs (NSAIDs) among different practice categories in Indian clinical setting. Eur J Clin Pharmacol. 2005;60:889-92.

8. Rahman MS, Begum ZA, Samad MK. Prescribing pattern of non-steroidal anti-inflammatory drugs at outpatient departments of teaching hospitals. Bangladesh J Pharmacol. 2007;2:1-6.

9. Manohar VS, Vinay M, Jayasree T, Kishan PV, Ubedulla S, Dixit R. Prescribing pattern of gastroprotective agents with non-steroidal antiinflammatory drugs. J Pharmacol Pharmacother. 2013;4:59-60.

10. Nonsteroidal Antiinflammatory Drugs and Antipyretic-Analgesics. In: KD Tripathi; Essentials of Medical Pharmacology. $7^{\text {th }}$ ed. New Delhi: Jaypee brothers; 2013:192-209.

11. Usher C, Bennett K, Teeling M, Feely J. Characterizing new users of NSAIDs before and after rofecoxib withdrawal. Br J Clin Pharmacol. 2006:64(4):494-7.

12. Vogt MT, Henderson BF, Duggal A, Ansani NT, Gillespie J, Starz T. NSAID usage: impact of safety data and product withdrawals on prescribing trends. P\&T Journal. 2007;32(5):284-7.

13. Samad MK. Consumption patterns of non-steroidal anti-inflammatory drugs by the community without prescription in Dhaka city. Bangladesh J Pharmacol. 2009;4:43-5.

14. Lanas A, Garci-Tell G, Armada B, Oteo-Alvaro. Prescription patterns and appropriateness of NSAID therapy according to gastrointestinal risk and cardiovascular history in patients with diagnoses of osteoarthritis. BMC Med. 2011;9:38.

15. Amaro F, Machan S, Carmona L, Alvaro GI, Daaz GF. Pattern of use and safety of non-steroidal antiinflammatory drugs in rheumatoid arthritis patients. A prospective analysis from clinical practice. Reumatol Clin. 2009;5(6):252-8. 
16. Jaksch W, Dejaco C, Schirmer M. 4 years after withdrawal of rofecoxib where do we stand today? Rheumatol Intern. 2008;28(12):1187-95.

17. Sharma T, Dutta S, Dhasmana DC. Prescription pattern of NSAIDs in orthopaedic OPD of a tertiary care teaching Hospital in Uttaranchal. JK Science. 2006;8(3):160-2.

18. Balat JD, Gandhi AM, Patel PP, Dikshit RK. A study of use of fixed dose combinations in Ahmedabad, India. Indian J Pharmacol. 2014;46(5):503-9.

19. Poudel A, Palaian S, Shankar PR, Jayasekara J, Izham MIM. Irrational fixed dose combinations in Nepal: Need for intervention. Kathmandu University Med J. 2008;6(3):399-405.

20. Kastury N, Singh S, Ansari KU. Fixed dose combinations and rational drug therapy. Indian $\mathrm{J}$ Pharmacol. 2001;33:458-9.

21. Introduction to drug utilization research. WHO collaborating centre for drug utilization research. WHO library catalogue. 2003:33.

22. Shankar PR, Upadhyay DK, Subish P, Bhandari RB, Das B. Drug utilization among older inpatients in a teaching Hospital in Western Nepal. Singapore Med J. 2010;51(1):28-34.

23. Ćalasan J, Mijatović V, Horvat O, Varga J, Sabo A, Stilinović N. The outpatient utilization of nonsteroidal anti-inflammatory drugs in South Bačka District, Serbia. Ind J Clin Pharmacol. 2011;33:24651.

24. Lee SH, Han CD, Yang IH, Ha CW. Prescription pattern of NSAIDs and the prevalence of NSAIDinduced gastrointestinal risk factors of Orthopaedic patients in clinical practice in Korea. J Korean Med Sci. 2011;26:561-7.

25. Gupta M, Malhotra S, Jain S, Aggarwal A, Pandhi P. Pattern of prescription of non-steroidal antiinflammatory drugs in orthopedic outpatient clinic of a North Indian tertiary care hospital. Indian $\mathbf{J}$ Pharmacol. 2005;37(6):404-5.

26. Teeling M, O`Connor H, Feely J, Bennett K. What therapies have replaced rofecoxib in Ireland? $\mathrm{Br} \mathrm{J}$ Clin Pharmacol. 2007;64(4):536-41.

Cite this article as: Kulkarni D, Kokila BN, Sahu SK, Kumar RG. Drug utilization 90\%: an innovative method in assessing quality of drug prescription with specific reference to non-steroidal antiinflammatory drugs prescription. Int J Basic Clin Pharmacol 2016;5:1746-51. 